\title{
Article \\ Effect of Pulmonary Inflammation by Surface Functionalization of Zinc Oxide Nanoparticles
}

\author{
Ayoung Jung ${ }^{\dagger}$, Sung-Hyun Kim ${ }^{\dagger} \mathbb{D}$, Jun-Young Yang, Jayoung Jeong, Jong Kwon Lee, Jae-Ho Oh and Jin Hee Lee * \\ Division of Toxicological Research, National Institute of Food and Drug Safety Evaluation, Ministry of Food and \\ Drug Safety, Osong, Cheongju 28159, Korea; kntp2002@korea.kr (A.J.); tjdgus32@korea.kr (S.-H.K.); \\ yangjy@korea.kr (J.-Y.Y.); 0jjy@korea.kr (J.J.); jkleest@korea.kr (J.K.L.); chopin68@korea.kr (J.-H.O.) \\ * Correspondence: tod98@korea.kr; Tel.: +82-43-719-5106; Fax: +82-43-719-5100 \\ + These authors contributed equally to this work.
}

check for

updates

Citation: Jung, A.; Kim, S.-H.; Yang, J.-Y.; Jeong, J.; Lee, J.K.; Oh, J.-H.; Lee, J.H. Effect of Pulmonary

Inflammation by Surface

Functionalization of Zinc Oxide Nanoparticles. Toxics 2021, 9, 336. https://doi.org/10.3390/ toxics 9120336

Academic Editors: Luc Ferrari and Pernille Høgh Danielsen

Received: 21 October 2021

Accepted: 2 December 2021

Published: 6 December 2021

Publisher's Note: MDPI stays neutral with regard to jurisdictional claims in published maps and institutional affiliations.

Copyright: (c) 2021 by the authors. Licensee MDPI, Basel, Switzerland. This article is an open access article distributed under the terms and conditions of the Creative Commons Attribution (CC BY) license (https:// creativecommons.org/licenses/by/ $4.0 /)$.

\begin{abstract}
Zinc oxide nanoparticles (ZnO NPs) are used in various industries such as food additives, cosmetics, and biomedical applications. In this study, we evaluated lung damage over time by three types of ZnO NPs (L-serine, citrate, and pristine) following the regulation of functional groups after a single intratracheal instillation to rats. The three types of $\mathrm{ZnO}$ NPs showed an acute inflammatory reaction with increased LDH and inflammatory cell infiltration in the alveoli $24 \mathrm{~h}$ after administration. Especially in treatment with L-serine, citrate ZnO NPs showed higher acute granulocytic inflammation and total protein induction than the pristine $\mathrm{ZnO} N \mathrm{Ns}$ at $24 \mathrm{~h}$. The acute inflammatory reaction of the lungs recovered on day 30 with bronchoalveolar fibrosis. The concentrations of IL- 4,6 , TNF- $\alpha$, and eotaxin in the bronchoalveolar lavage fluid (BALF) decreased over time, and the levels of these inflammation indicators are consistent with the following inflammatory cell data and acute lung inflammation by $\mathrm{ZnO}$ NP. This study suggests that single inhalation exposure to functionalized $\mathrm{ZnO}$ NPs may cause acute lung injury with granulocytic inflammation. Although it can recover 30 days after exposure, acute pulmonary inflammation in surface functionalization means that additional studies of exposure limits are needed to protect the workers that produce it.
\end{abstract}

Keywords: nanoparticles; zinc oxide; intratracheal instillation; bronchoalveolar lavage; acute inflammation

\section{Introduction}

In recent years, as the number of cases of applying nanomaterials in various industrial fields has increased, it has become a critical issue to identify the toxicity of nanomaterials accurately. Primarily, zinc oxide nanoparticles (ZnO NPs) are used in many commercial products, including food additives, cosmetics, textiles, paints, and personal hygiene products [1]. In addition, ZnO NPs are widely used as an ingredient of paints and coating and finishing materials in products and buildings because they provide long-term protection from ultraviolet light $[2,3]$.

The increasing use of ZnO NPs has raised concerns about their potential toxicity to humans and the environment. ZnO NPs might enter the human body by various routes, including oral ingestion, nasal inhalation, intravenous injection, and transdermal delivery [4-8]. Therefore, the toxicological properties of $\mathrm{ZnO}$ NPs have been studied according to the different routes of exposure. Nanoparticles can translocate into the blood and various organs from the respiratory tract and further induce lesions [9]. Many studies have evaluated the toxicity of $\mathrm{ZnO}$ NPs in cell lines and animal models [10-13]. The inhalation of low levels of $\mathrm{ZnO}$ NPs causes marked changes and damage to pulmonary function in guinea pigs [14], and $\mathrm{ZnO}$ inhalation causes pulmonary impairment and systemic effects such as metal fume fever in humans [15].

Recently, due to the development of biomedical applications, studies for the application of nanomaterials are in progress, and surface modification of nanomaterials is 
considered essential for application in various fields such as nanocarriers. The physicochemical parameters of nanomaterials have been investigated to affect cellular uptake, etc., and these studies provide important information on the toxicity potential of nanomaterials' surface modification [16-18].

In this study, the used $\mathrm{ZnO} N P$ is a nanomaterial discussed as a significant candidate for drug delivery, treatment, and diagnosis [19]. However, the inflammatory response to $\mathrm{ZnO}$ NPs in relation to the surface functionalization of $\mathrm{ZnO}$ NPs is not clearly understood. Therefore, we used surface-modified (pristine, L-serine, and citrate) ZnO NPs to evaluate the time-point inflammatory responses to respiratory exposure.

\section{Materials and Methods}

\subsection{Preparation and Characterization of $\mathrm{ZnO} N P s$}

The pristine $20 \mathrm{~nm}$ sized $\mathrm{ZnO}$ NPs were purchased from Sumitomo Osaka Cement Co, Ltd. (Lot number: 141319; Tokyo, Japan). For the pristine ZnO NPs, surface modification was performed to provide surface functionalization according to previously described methods [20,21]. The primary size and morphology of ZnO NPs were measured by scanning electron microscopy (SEM) using Quanta 250 FEG instrument (FEI Co., Hillsboro, OR, USA). The hydrodynamic size and zeta potentials of the ZnO NPs were measured using a Zetasizer Nano ZS (Malvern panalytical, Malvern, UK) in distilled water (DW). Endotoxin was evaluated using an Endpoint Chromogenic Limulus Amoebocyte Lysate assay (Cambrex Corporation, Walkersville, MD, USA).

\subsection{Animals and $\mathrm{ZnO} \mathrm{NPs}$ Exposure}

Six-week-old specific pathogen-free (SPF) male Wistar rats (200-250 g) were purchased from Samtako (Samtako Bio, Gyeonggi-do, Korea). The animal room was maintained at $20 \pm 2{ }^{\circ} \mathrm{C}, 60 \pm 10 \%$ relative humidity, and a $12 \mathrm{~h}$ light/dark cycle. Distilled water (DW) and sterilized food were available ad libitum to the rats. They were acclimated to this environment for five days prior to dosing. This study was approved by the Institutional Animal Care and Use Committee (IACUC) of the Ministry of Food and Drug Safety (MFDS) (2018, Approval NO. MFDS-18-145). All experimental procedures conformed to the guide and use of laboratory animals. Rats were randomly divided into four groups $(n=5$ per group): the vehicle (VEH) control group ( $0.9 \%$ saline) and three experimental groups ( $\mathrm{ZnO}$ NPs modified with pristine, L-serine, and citrate). The experimental groups were intratracheal instilled with single-dose ZnO NPs of $300 \mu \mathrm{g}$ per rat (volume of $0.5 \mathrm{~mL}$ ) and evaluated 1 and 30 days after, respectively. Test nanoparticle suspension was prepared and dispersed in $0.9 \%$ saline. Then, it was ultrasonically dispersed immediately before administration to animals. The experimental concentration was set by referring to the literature [22]. The control group was treated with $0.9 \%$ saline. In the experimental rats, the ZnO NP suspension was administered via intratracheal instillation after they were anesthetized using isoflurane. Instillation of NPs was performed using methods previously described by Lu et al. [21]. At the end of the experiments, the rats were anesthetized by tiletamine-zolazepam (Zoletil ${ }^{\circledR}$ ) (Virbac, Fort Worth, TX, USA) at $50 \mathrm{mg} / \mathrm{kg}$ body weight and sacrificed by exsanguination via the abdominal aorta.

\subsection{Bronchoalveolar Lavage Fluid Analysis and Cytokine Expression}

Bronchoalveolar lavage fluid (BALF) samples were prepared as described previously [23]. BALF was collected by cannulating the trachea and lavaging the lungs three times with $1 \mathrm{~mL}$ of cold sterile PBS free of $\mathrm{Ca}^{2+}$ and $\mathrm{Mg}^{2+}$. Approximately $2 \mathrm{~mL}$ of BALF per rat were collected and pooled in sterile centrifuge tubes. The BALF was centrifuged $\left(800 \times \mathrm{g}\right.$ for $10 \mathrm{~min}$ at $4{ }^{\circ} \mathrm{C}$ ) and the total protein was determined in the first $2 \mathrm{~mL}$ of BALF by the bicinchoninic acid (BCA) assay (Sigma-Aldrich, St. Louis, MO, USA). Lactate dehydrogenase (LDH) was assayed with a commercial diagnostics kit (Roche Diagnostics Ltd., Burgess Hill, UK). All lavage fluid was pooled and centrifuged at $250 \times g$ for $10 \mathrm{~min}$ at $4{ }^{\circ} \mathrm{C}$. The resulting BALF cell pellet was diluted. Aliquots were analyzed by a hemocy- 
tometer and trypan blue dye exclusion for viable cell count and by light microscopy of Diff-Quik-stained (Polysciences) cytospin preparations for cell differentiation. The inflammatory cytokine, interleukin (IL)-4, IL-6, tumor necrosis factor-alpha (TNF- $\alpha$ ), and eotaxin in non-diluted BALF were measured using the duoset ELISA kit (R\&D System Europe Ltd., Abingdon, UK) and performed according to the manufacture's procedure. The values of the samples obtained at the two time points ( 1 day and 30 days) were statistically analyzed by comparing them with the results of the vehicle control group at each time point.

\subsection{Histopathology}

Lungs from the mice of the vehicle control group and treated groups were fixed with $10 \%$ neutral buffered formalin and processed according to routine histological techniques. After paraffin embedding, $5 \mu \mathrm{m}$ sections were cut and stained with hematoxylin and eosin ( $\mathrm{H} \& \mathrm{E})$ for histopathologic evaluation. For the assessment of lung injury, the airways, terminal bronchioles, and lung parenchyma were examined microscopically to evaluate cellular changes and inflammation.

\subsection{Statistical Analysis}

Experimental data were expressed as mean \pm standard error of the mean (SEM). The data were analyzed and plotted using GraphPad software (ver. 5; GraphPad Software Inc., La Jolla, CA, USA). All results were compared by one-way ANOVA with post hoc Tukey's pair-wise analysis. $p$ values of less than $5 \%(p<0.05)$ were considered statistically significant.

\section{Results}

\subsection{Physicochemical Properties of $\mathrm{ZnO} N P s$}

The physicochemical properties of ZnO NPs are summarized in Table 1. To evaluate the colloidal properties and behavior of ZnO NPs in aqueous systems, we investigated the particle size and morphology of ZnO NPs dispersed in deionized water. The three types of $\mathrm{ZnO}$ nanoparticles with a primary size of approximately $26-27 \mathrm{~nm}$ were shown to aggregate in water to a size of 219-399 $\mathrm{nm}$. In addition, the SEM image showed agglomerated morphology between particles, including spherical features (Figure 1). As for the zeta potentials, the pristine group showed a charge of approximately $21 \mathrm{mV}, \mathrm{ZnO}$ with an L-serine group attached to it showed a charge of about $30 \mathrm{mV}$, and $\mathrm{ZnO}$ with a citrate group had a charge of $-36 \mathrm{mV}$. The contamination by endotoxin was not observed for all substances.

Table 1. Physicochemical properties of three types of ZnO NPs.

\begin{tabular}{cccc}
\hline \multicolumn{1}{c}{ Modification } & \multicolumn{2}{c}{ 20 nm ZnO NPs } \\
\hline Measurements & Pristine & L-Serine & Citrate \\
\hline Primary size (nm) $^{\mathrm{a}}$ & $26.8 \pm 4.5$ & $27.1 \pm 7.5$ & $26.9 \pm 4.3$ \\
Hydrodynamic size (nm) $^{\mathrm{b}}$ & $399 \pm 16$ & $219 \pm 3$ & $341 \pm 61$ \\
Polydispersity (PDI) $^{\mathrm{b}}$ & $0.50 \pm 0.02$ & $0.62 \pm 0.07$ & $0.63 \pm 0.06$ \\
Zeta potential (mV) $^{\mathrm{b}}$ & $21.4 \pm 4.6$ & $30.0 \pm 3.4$ & $-36.0 \pm 2.6$ \\
Endotoxin (Unit/mL) & $<0.1$ & $<0.1$ & $<0.1$ \\
\hline
\end{tabular}

$\overline{{ }^{a}}$ Primary size was measured by scanning electron microscopy (SEM) data. ${ }^{\mathrm{b}}$ Hydrodynamic size, polydispersity, and zeta potential were measured in distilled water (DW). The information on surface-modified $20 \mathrm{~nm} \mathrm{ZnO}$ nanoparticles was taken from the literature previously reported by Yang et al. [20].

\subsection{Bronchoalveolar Lavage Fluid Analysis}

To evaluate the inflammatory pattern of differential ZnO NPs over time, a cytological analysis of BALF was performed (Figures 2 and 3). Then, 1 and 30 days after $\mathrm{ZnO}$ NP injection, the total cells of BALF were higher than those of vehicles in all three groups (Figure 2A). The $\mathrm{ZnO}$ group with L-Serine (positive charge induction) and citrate (positive charge induction) functional groups induced a significant increase in granulocytes on day 1 
and recovered to the control level after 30 days (Figure 2C). The pristine group induced relatively lower granulocytes than the surface-functionalized L-serine and citrate groups, and macrophages and neutrophils were observed mainly in BALF (Figures 2B and 3B).
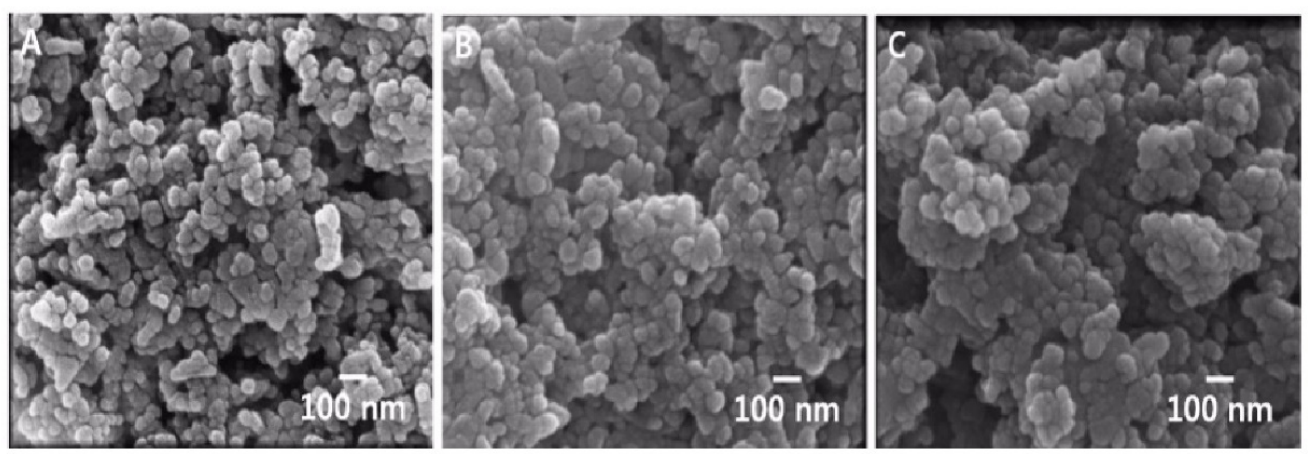

Figure 1. Scanning electron microscopy (SEM) image of three types of ZnO NPs. ZnO NPs were deposited on SEM grids and directly observed. SEM image showing that ZnO NPs were uniformly spherical (A) $20 \mathrm{~nm}$ ZnO NPs (pristine), (B) $20 \mathrm{~nm}$ ZnO NPs (L-serine), and (C) $20 \mathrm{~nm} \mathrm{ZnO} \mathrm{NPs} \mathrm{(citrate).} \mathrm{(Scale} \mathrm{bar} \mathrm{=} 100 \mathrm{~nm}$ ). The information on surface-modified $20 \mathrm{~nm}$ $\mathrm{ZnO}$ nanoparticles was taken from the literature previously reported by Yang et al. [20].
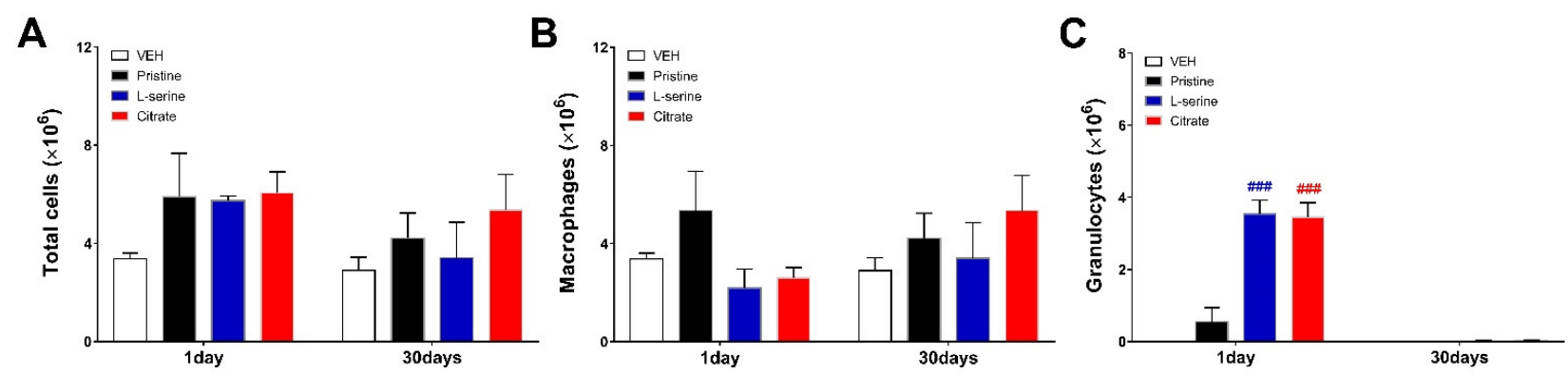

Figure 2. Differential cells in bronchoalveolar lavage fluid (BALF) from rat lungs at days 1 and 30 after a single instillation of ZnO NP groups. Number of (A) total cells, (B) macrophages, and (C) granulocytes. Data are expressed mean \pm standard error of the mean (SEM) $(n=5)$. Significance versus vehicle $(\mathrm{VEH})$ control: \#\#\# $p$ value $<0.0001$.

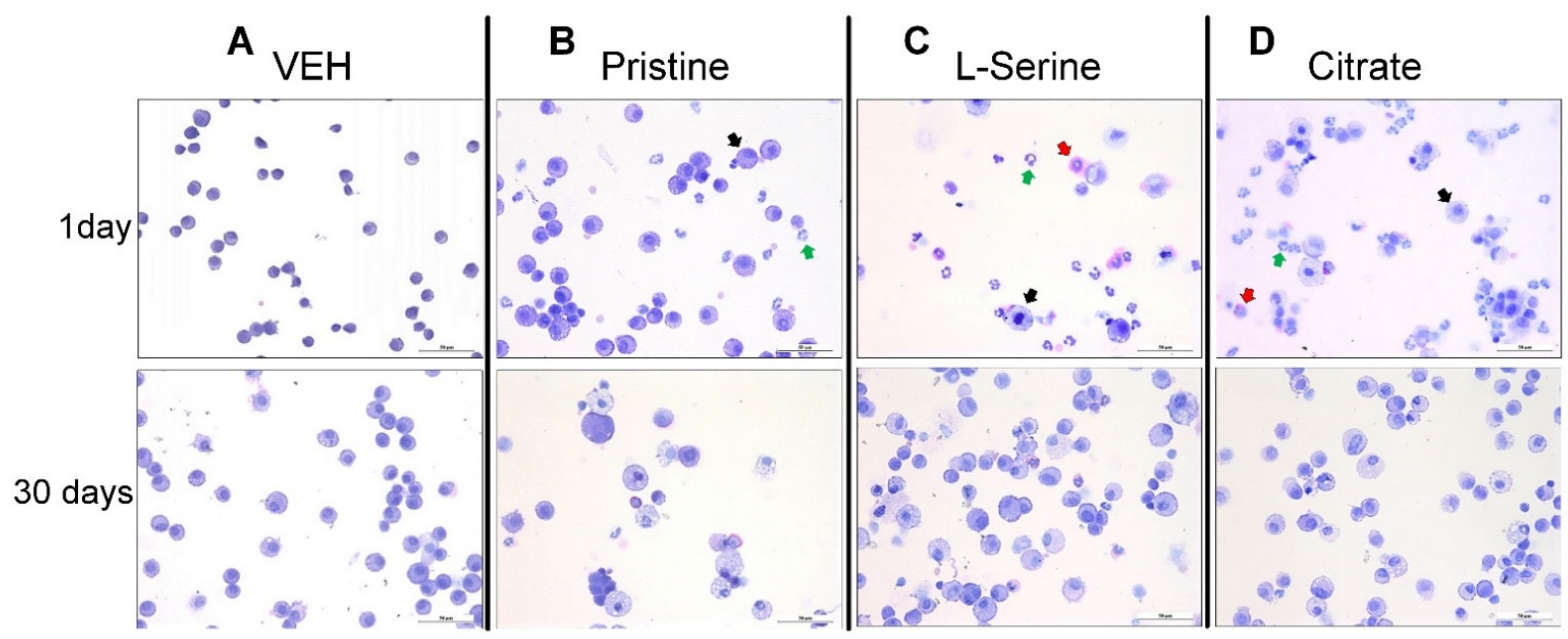

Figure 3. Morphology of differential cells in bronchoalveolar lavage fluid (BALF) from rat lungs at days 1 and 30 after a single instillation of ZnO NP groups. Representative BALF cell images (cytospin preparation stained with Diff-Quik) after intratracheal instillation of ZnO NPs groups: (A) vehicle control (VEH); and ZnO NPs groups of (B) pristine, (C) L-serine, and (D) citrate. Pictures were taken at $\times 200$ magnification (scale bar $=50 \mu \mathrm{m}$, red arrows $=$ eosinophil, green arrows $=$ neutrophil, and black arrows = macrophage). 


\subsection{Changes in Biochemical Indicators following Instillation with $\mathrm{ZnO} N \mathrm{NS}_{\mathrm{s}}$}

The LDH enzymes are distributed widely in the cytosol during the conversion of lactate to pyruvate. The NP's cytotoxicity might break the plasma membrane integrity, causing LDH to leak into BALF, with an increase in extracellular levels. The level of LDH was highest on the first day after administration (Figure 4A). The total protein, a marker for vascular permeability, significantly increased at day 1 in the functionalized (L-serine and citrate) $\mathrm{ZnO} N$ Ps groups compared with the vehicle control and pristine group (Figure 4B). On day 30 after instillation, the levels of LDH and total protein in all groups recovered to the control level.

A

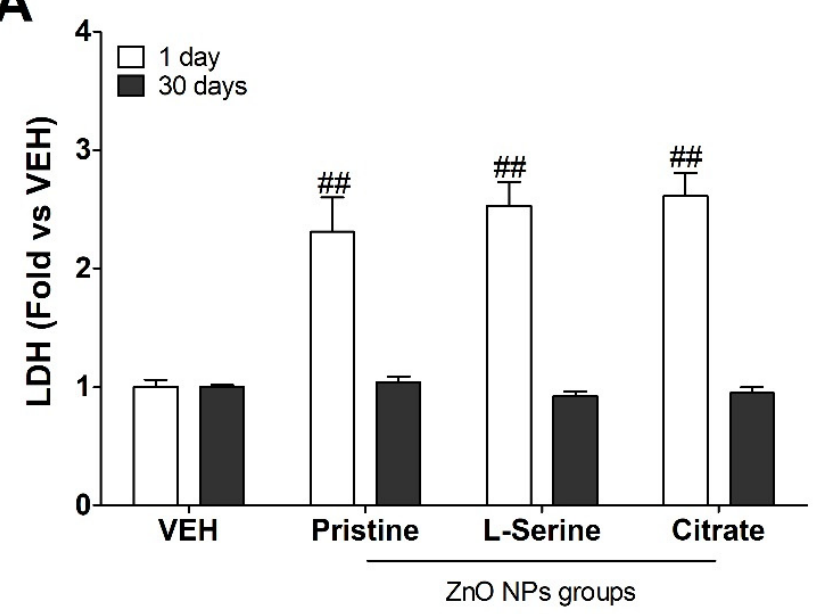

B

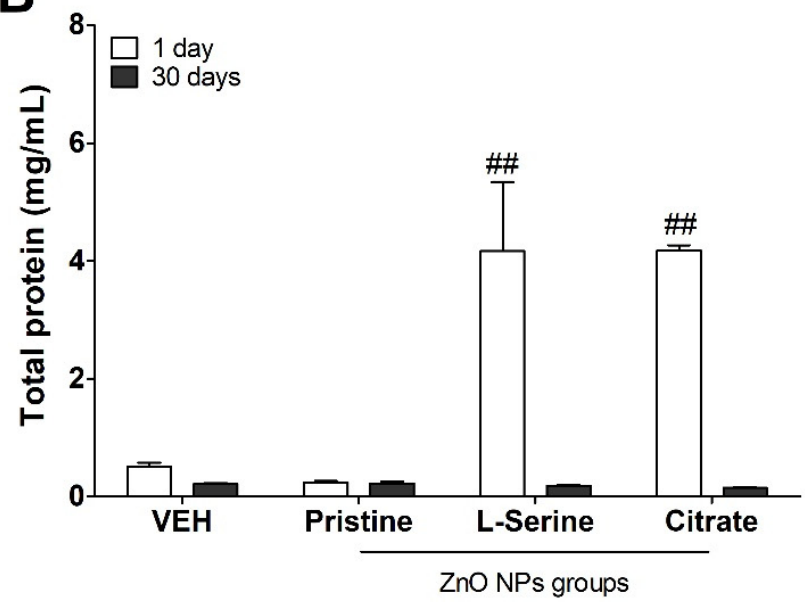

Figure 4. Lactate dehydrogenase (LDH) and total protein in rat lungs following intratracheal instillation of differential functionalized $\mathrm{ZnO}$ NPs. Level of (A) LDH and (B) total protein from 1 to 30 days in bronchoalveolar lavage fluid (BALF). Data are expressed mean \pm standard error of the mean (SEM) $(n=5)$. Significance versus vehicle (VEH) control: \#\# $p$ value $<0.001$.

\subsection{Inflammatory Cytokine Expression following Instilled with $\mathrm{ZnO} N P s$}

To identify inflammatory responses induced by the instillation of differential ZnO NP groups, the levels of inflammatory cytokines were measured in the BALF (Figure 5). IL-4 is a cytokine that induces the differentiation of helper T cells into Th2 cells. The level of IL-4 showed a control or lower value on day 1 and day 30 (Figure 5A). IL-6 can act as both proand anti-inflammatory cytokines, and levels of IL-6 increased significantly on day 1 in the $\mathrm{ZnO} N$ Ps-instilled group functionalized with L-serine and citrate rather than the pristine group. Then, it decreased sharply on day 30 after intratracheal instillation (Figure 5B). TNF$\alpha$ is a cell-signaling cytokine involved in systemic inflammation and one of the cytokines responsible for causing the acute phase reaction. Regardless of the functional group, TNF- $\alpha$ levels were significantly increased at day 1 in the ZnO NPs-instilled groups, decreasing by day 30 after the instillation (Figure 5C). Eotaxin is a CC chemokine subfamily of eosinophil chemotactic proteins, and functionalized $\mathrm{ZnO}$ NPs groups significantly increased the level of eotaxin on day 1 rather than the pristine group (Figure 5D). Eotaxin also recovered to the control level on day 30. 
A
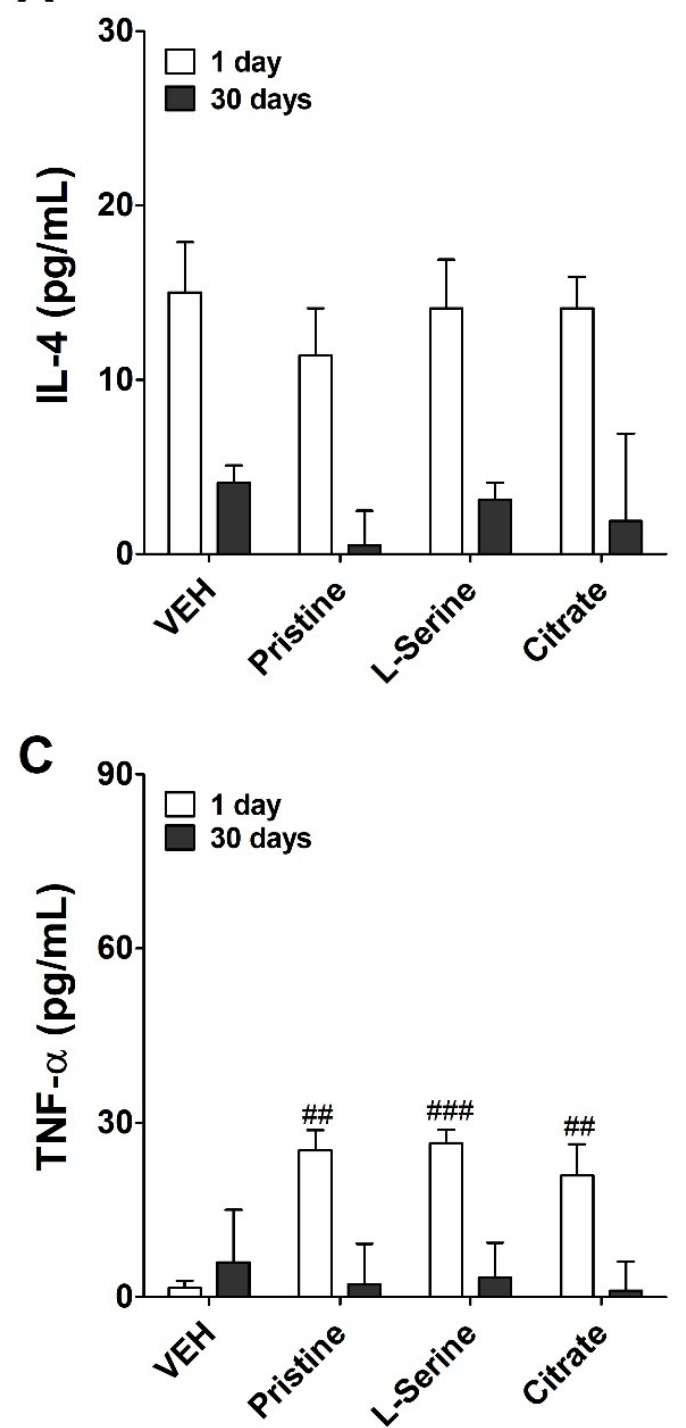

B
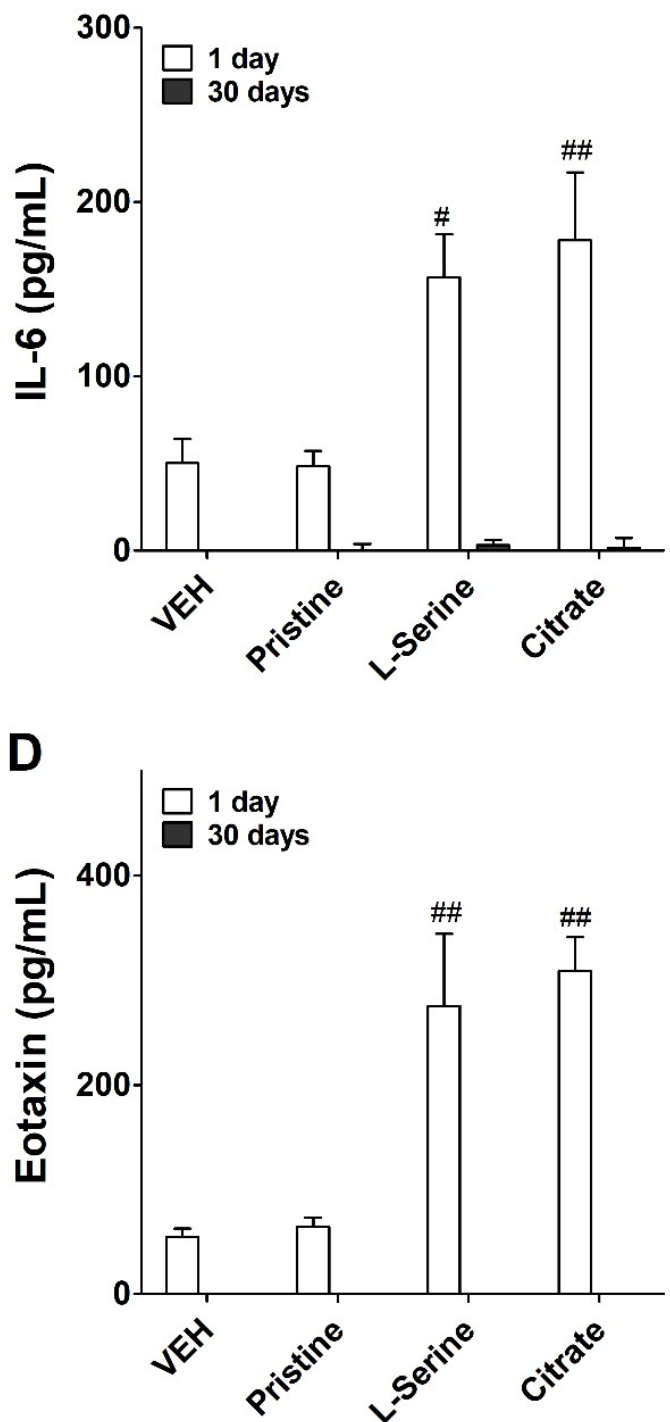

Figure 5. Evaluation of inflammatory cytokines cells in bronchoalveolar lavage fluid (BALF) from rat lungs at day 1 and 30 after a single instillation of ZnO NPs. Level of (A) interleukin (IL)-4, (B) IL-6, (C) tumor necrosis factor (TNF) $-\alpha$, and (D) eotaxin. Data are expressed means \pm standard error of the mean $(\mathrm{SEM})(n=5)$. Significance versus vehicle $(\mathrm{VEH})$ control: \# $p$ value $<0.05$, \#\# $p$ value $<0.001$, and \#\#\# $p$ value $<0.0001$.

\subsection{Histopathology}

Figure 6 presented histological lesions at $24 \mathrm{~h}$ and 30 days of single exposure with a group of functionalized $\mathrm{ZnO}$ NPs. In acute inflammation $24 \mathrm{~h}$ after instillation of all $\mathrm{ZnO} \mathrm{NP}$ groups, inflammatory cells including neutrophils infiltrate the alveolar and bronchoalveolar junction. Infiltration of inflammatory cells led to an increase in the alveolar wall thickness. This was consistent with BALF cell analysis data (Figures 2 and 6). For example, in all $\mathrm{ZnO}$ groups, the increase in alveolar granulocytes increased on day 1 and recovered on day 30, regardless of functional group, and a recovery pattern accompanied by fibrosis was observed in lung tissue as it also progressed from day 1 to day 30 . However, in contrast, the pristine group, which had relatively few granulocytes in the BALF cell analysis, clearly showed high granulocyte penetration in the alveolar and bronchoalveolar junction. 


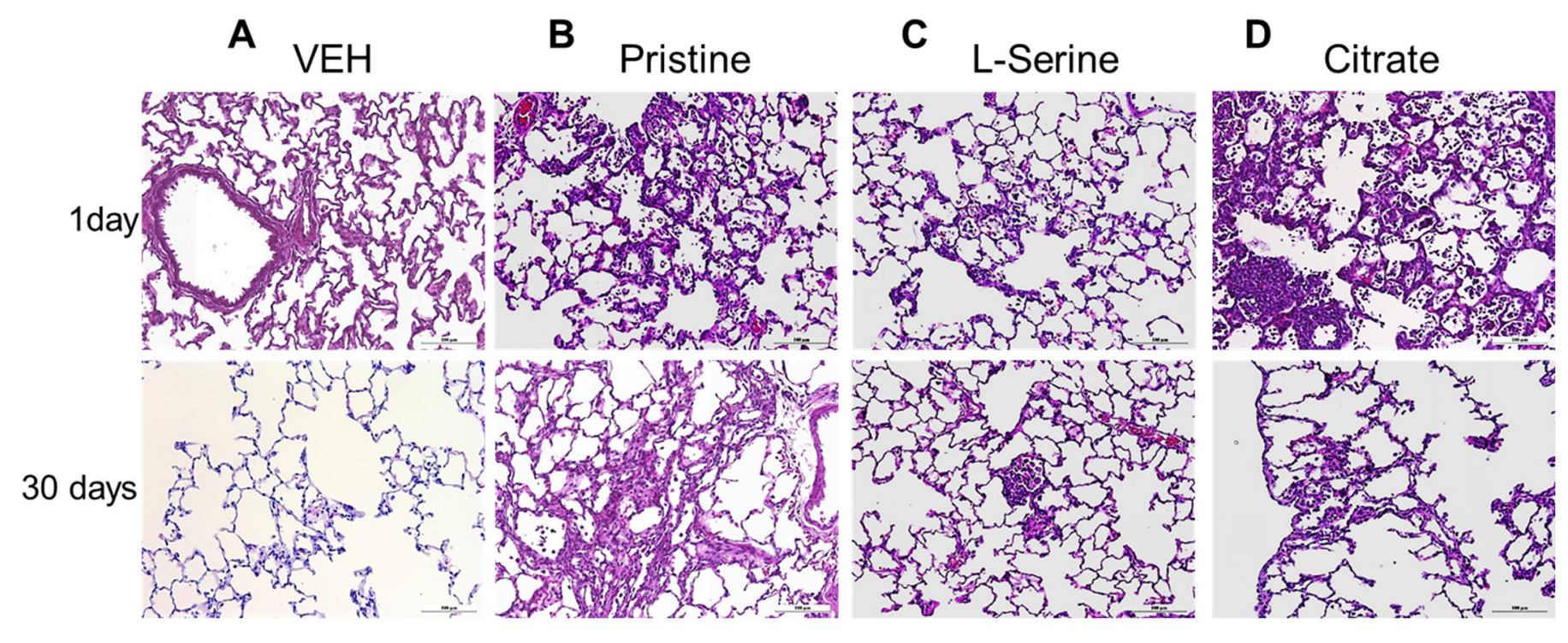

Figure 6. Lung histopathology of rat at day 1 and 30 after a single instillation of ZnO NPs. Representative lung images (stained with $\mathrm{H} \& \mathrm{E}$ ) after intratracheal instillation of $20 \mathrm{~nm} \mathrm{ZnO} \mathrm{NPs} \mathrm{groups:} \mathrm{(A)} \mathrm{vehicle} \mathrm{(VEH)} \mathrm{control,} \mathrm{(B)} \mathrm{pristine,}$ (C) L-serine, and (D) citrate ZnO NPs group. Day 1, infiltration of granulocytes in alveoli was observed (B-D, 1 day). Day 30 , fibrosis in alveolar wall was observed (B-D, 30 days). Pictures were taken at $\times 200$ magnification (Scale bars $=50 \mu \mathrm{m})$.

\section{Discussion}

The US National Nanotechnology Initiative defines nanomaterials as materials with at least one dimension in the range of 1-100 $\mathrm{nm}$ [24]. Significant increases in production and demand could lead to unintended exposures to nanomaterials not only by workers in certain industries, but also by end-product users via inhalation, dermal absorption, and gastrointestinal tract absorption [25]. Because of their unique properties, including small size and a corresponding large specific surface area, nanomaterials are believed to impose different degrees of biological effects from those of microscale materials [26]. Inhalation studies show that, in comparison with their larger-sized counterparts, nanoparticles penetrate deeper into the lungs and become localized within various cell types, inducing a more significant inflammatory response associated with marked potential toxicity $[7,27,28]$.

$\mathrm{ZnO}$ NPs are representative nanomaterials that can be used in biomedical applications such as biosensors. For example, $\mathrm{ZnO} \mathrm{NPs}$ or $\mathrm{ZnO}$ composites are applied for vaccineadjuvant use because the form of NPs can efficiently present antigens to dendritic cells (DCs) with subsequent adequate inflammation [29,30]. However, many studies have been reported on the inhalation toxicity of $\mathrm{ZnO}$ NPs, but little information is available on the effects of surface-modified $\mathrm{ZnO}$ NPs exposure to the lungs.

The ZnO NPs synthesized with three different functional groups (pristine, L-serine, and citrate) were used in the current study, as described in the previously reported literature [20]. Since a total of three types of NPs groups share the same core (ZnO NPs), it was confirmed that they have very similar primary sizes and shapes. By the functional groups of the NPs, ZnO containing L-serine exhibited a positive charge, and $\mathrm{ZnO}$ containing citrate exhibited a negative charge. However, we could not find any evidence of a specific toxicity correlation according to the differential surface charge of the synthesized ZnO NPs. The presence of endotoxin can lead to inflammation of the lungs, resulting in distortion of the test substance's results [31]. We evaluated the endotoxin contamination of the test substance before the test, removing the influence of the endotoxin impurity of the test substance and securing the reliability of the result.

Intratracheal injection of functionalized (L-serine and citrate) ZnO NPs significantly increased the total protein in BALF on day 1, consistent with the BALF cytometric results. The increase in total protein, an indicator of vascular permeability of inflammatory cells, promoted the migration of granulocytes from blood vessels to tissues [32]. In the case 
of pristine $\mathrm{ZnO}$ NPs, the BALF analysis results showed that granulocytes were recruited higher than those of the control group. Still, inflammation by macrophages appeared to be mainly on day 30 after instillation, when inflammatory cells of macrophages and granulocytes decreased, and the levels of LDH and total protein, which are cytotoxic indicators, were also decreased. As reported, $\mathrm{ZnO}$ nanoparticles induced acute $(24 \mathrm{~h})$ inflammation, and a similar trend was observed to recover over time (30 days) [22]. As can be seen through the rat lung at 30 days after administration, the number of inflammatory cells clearly decreased in the alveoli. Beyond the presentation of some localized inflammation, fibrosis and recovery were observed as well.

The results of inflammatory cytokine analysis in BALF showed that the cytokine levels in rats treated with all $\mathrm{ZnO}$ NPs were generally increased compared to the control group. Of these cytokines, IL- 6 and TNF- $\alpha$ were prominently affected by ZnO NPs treatment. These cytokines are representative pro- and anti-inflammatory cytokines, respectively. IL-6 acts as a pleiotropic cytokine, with important biological effects on inflammation, immunity, and stress [33]. Researchers have confirmed the ability of ZnO NPs to induce TNF- $\alpha$ or IL-6 production in purified primary cell cultures or toxicological evaluation [10]. It is noteworthy that the inhalation of ultrafine $\mathrm{ZnO}$ NPs in occupational settings can increase the expression of these cytokines, which is symptomatically recognized as metal fume fever in welders [34]. The genes of these IL-6 play pivotal roles in the inflammation induced by $\mathrm{ZnO}$ NPs when the treatment doses are high. In this study, as a result of cytokine analysis of the pristine group (Figure 5C), an inflammatory response by macrophages induced an increase in TNF-alpha. On the other hand, the induction of IL-6 cytokines was not made. As a result, it is estimated that the recruitment of granulocytes is remarkably low because pristine $\mathrm{ZnO}$ nanoparticles do not induce IL-6 (Figures 2C and 5B). Another study using IL-6 gene silencing showed that, in induced lung fibrosis, IL-6 played an important role in the regulation of the expression of Th2 cytokines (IL-4 and IL-5) [35]. However, in our study, the induction of IL-4, a Th2-related cytokine, was very insignificant.

Although it cannot be confirmed in the current study, it is possible that other pathways promoted the increase in eotaxin. In addition, the IL- 6 receptor regulates fibrosis in tissues by regulating the profibrotic cytokine [35-37]. The ability of ZnO NPs to induce TNF- $\alpha$ may also help regulate acute inflammation and promote Th1 differentiation [22]. As another role, it has been reported that the TNF- $\alpha$ can induce the accumulation of eotaxin mRNA in lung epithelial cell lines A549 and BEAS 2B in a dose-dependent manner [38]. Further research will be needed, but it is assumed that the increased levels of eotaxin in our study were affected by the TNF-alpha cytokine. Eosinophils play a key role in mediating asthma and other allergic conditions, and ZnO NPs can induce eosinophilic to severely cytotoxic inflammation [38]. Eotaxin is a chemokine that plays a vital role in recruiting eosinophils. Moreover, as previously reported, lung exposure of $\mathrm{ZnO}$ NPs has been shown to induce eosinophil-related inflammation at $24 \mathrm{~h}$ [22].

In this study, tests were conducted with two limited functional groups, L-serine and citrate, but more diverse functional groups can be attached to the surface of actual nanomaterials $[39,40]$. In the field of biomedical engineering, there is an active movement to utilize surface-functionalized nanomaterials; thus, in order to secure the safety of nanomaterials modified with functional groups, it is necessary to accumulate toxicity data through more studies.

The intratracheal instillation method used in this study has the advantage of being able to inject a solution with a precisely quantified concentration into the lungs. However, in actual exposure cases, individual subjects may not be inhaled at exactly the same amount, so it is necessary to establish an endpoint of toxicity through multi-disciplinary studies.

\section{Conclusions}

The results found in this study indicate that exposed ZnO NPs to the lungs induced potent but reversible inflammation in the acute phase, which recovered 30 days after instillation. In addition, although no obvious difference was observed according to the 
functional groups, it suggests that when L-serine and citrate functional groups are attached to the core, the production of IL-6 and eotaxin can be increased, thereby promoting the recruitment of granulocytes.

Author Contributions: Conceptualization, A.J. and J.J.; experiments and analysis, A.J., J.-Y.Y. and J.K.L.; formal analysis, S.-H.K.; investigation, J.-Y.Y. and J.K.L.; writing—original draft preparation: A.J. and S.-H.K.; writing-review and editing: J.H.L., J.-H.O. and S.-H.K.; project administration and supervision: J.J. and J.-H.O. All authors have read and agreed to the published version of the manuscript.

Funding: This study was supported by grants from the Ministry of Food and Drug Safety, Korea (18181MFDS361).

Institutional Review Board Statement: This study was approved by the Institutional Animal Care and Use Committee (IACUC) of Ministry of Food and Drug Safety (2018, Approval NO. MFDS-18-145).

Informed Consent Statement: Not applicable.

Data Availability Statement: The original contributions presented in the study are included in the article further inquiries can be directed to the corresponding authors.

Conflicts of Interest: The authors declare that they have no known competing financial interests or personal relationships that could have appeared to influence the work reported in this paper.

\section{References}

1. Liu, W. Nanoparticles and their biological and environmental applications. J. Biosci. Bioeng. 2006, 102, 1-7. [CrossRef]

2. Ju-Nam, Y.; Lead, J.R. Manufactured nanoparticles: An overview of their chemistry, interactions and potential environmental implications. Sci. Total Environ. 2008, 400, 396-414. [CrossRef] [PubMed]

3. Li, N.; Xia, T.; Nel, A.E. The role of oxidative stress in ambient particulate matter-induced lung diseases and its implications in the toxicity of engineered nanoparticles. Free Radic. Biol. Med. 2008, 44, 1689-1699. [CrossRef] [PubMed]

4. Gao, L.; Yang, S.; Li, S.; Meng, Y.; Wang, H.; Lei, H. Acute toxicity of zinc oxide nanoparticles to the rat olfactory system after intranasal instillation. J. Appl. Toxicol. 2013, 33, 1079-1088. [CrossRef] [PubMed]

5. Pasupuleti, S.; Alapati, S.; Ganapathy, S.; Anumolu, G.; Pully, N.R.; Prakhya, B.M. Toxicity of zinc oxide nanoparticles through oral route. Toxicol. Ind. Health 2012, 28, 675-686. [CrossRef]

6. Surekha, P.; Kishore, A.S.; Srinivas, A.; Selvam, G.; Goparaju, A.; Reddy, P.N.; Murthy, P.B. Repeated dose dermal toxicity study of nano zinc oxide with Sprague-Dawley rats. Cutan. Ocul. Toxicol. 2012, 31, 26-32. [CrossRef] [PubMed]

7. Wang, B.; Feng, W.; Wang, T.; Jia, G.; Wang, M.; Shi, J.; Zhang, F.; Zhao, Y.; Chai, Z. Acute toxicity of nano-and micro-scale zinc powder in healthy adult mice. Toxicol. Lett. 2006, 161, 115-123. [CrossRef]

8. Wang, B.; Feng, W.; Wang, M.; Wang, T.; Gu, Y.; Zhu, M.; Ouyang, H.; Shi, J.; Zhang, F.; Zhao, Y. Acute toxicological impact of nano-and submicro-scaled zinc oxide powder on healthy adult mice. J. Nanopart. Res. 2008, 10, 263-276. [CrossRef]

9. Baek, M.; Kim, M.; Cho, H.; Lee, J.; Yu, J.; Chung, H.; Choi, S. Factors influencing the cytotoxicity of zinc oxide nanoparticles: Particle size and surface charge. J. Phys. Conf. Ser. 2011, 304, 012044. [CrossRef]

10. Xia, T.; Kovochich, M.; Liong, M.; Madler, L.; Gilbert, B.; Shi, H.; Yeh, J.I.; Zink, J.I.; Nel, A.E. Comparison of the mechanism of toxicity of zinc oxide and cerium oxide nanoparticles based on dissolution and oxidative stress properties. ACS Nano 2008, 2, 2121-2134. [CrossRef]

11. Yang, H.; Liu, C.; Yang, D.; Zhang, H.; Xi, Z. Comparative study of cytotoxicity, oxidative stress and genotoxicity induced by four typical nanomaterials: The role of particle size, shape and composition. J. Appl. Toxicol. 2009, 29, 69-78. [CrossRef] [PubMed]

12. Sayes, C.M.; Reed, K.L.; Warheit, D.B. Assessing toxicity of fine and nanoparticles: Comparing in vitro measurements to in vivo pulmonary toxicity profiles. Toxicol. Sci. 2007, 97, 163-180. [CrossRef] [PubMed]

13. De Berardis, B.; Civitelli, G.; Condello, M.; Lista, P.; Pozzi, R.; Arancia, G.; Meschini, S. Exposure to ZnO nanoparticles induces oxidative stress and cytotoxicity in human colon carcinoma cells. Toxicol. Appl. Pharmacol. 2010, 246, 116-127. [CrossRef] [PubMed]

14. Lam, H.; Chen, L.; Ainsworth, D.; Peoples, S.; Amdur, M. Pulmonary function of guinea pigs exposed to freshly generated ultrafine zinc oxide with and without spike concentrations. Am. Ind. Hyg. Assoc. J. 1988, 49, 333-341. [CrossRef] [PubMed]

15. Fine, J.M.; Gordon, T.; Chen, L.C.; Kinney, P.; Falcone, G.; Beckett, W.S. Metal fume fever: Characterization of clinical and plasma IL-6 responses in controlled human exposures to zinc oxide fume at and below the threshold limit value. J. Occup. Environ. Med. 1997, 39, 722-726. [CrossRef] [PubMed]

16. Kim, K.; Kim, T.; Kim, H.; Kim, H.; Gwak, G.; Paek, S.; Oh, J. Colloidal behaviors of ZnO nanoparticles in various aqueous media. Toxicol. Environ. Health Sci. 2012, 4, 121-131. [CrossRef] 
17. Heng, B.C.; Zhao, X.; Xiong, S.; Ng, K.W.; Boey, F.Y.; Loo, J.S. Toxicity of zinc oxide (ZnO) nanoparticles on human bronchial epithelial cells (BEAS-2B) is accentuated by oxidative stress. Food Chem. Toxicol. 2010, 48, 1762-1766. [CrossRef]

18. Huang, C.; Aronstam, R.S.; Chen, D.; Huang, Y. Oxidative stress, calcium homeostasis, and altered gene expression in human lung epithelial cells exposed to ZnO nanoparticles. Toxicol. Vitr. 2010, 24, 45-55. [CrossRef] [PubMed]

19. Senapati, V.A.; Kumar, A.; Gupta, G.S.; Pandey, A.K.; Dhawan, A. ZnO nanoparticles induced inflammatory response and genotoxicity in human blood cells: A mechanistic approach. Food Chem. Toxicol. 2015, 85, 61-70. [CrossRef]

20. Yang, J.; Bae, J.; Jung, A.; Park, S.; Chung, S.; Seok, J.; Roh, H.; Han, Y.; Oh, J.; Sohn, S. Surface functionalization-specific binding of coagulation factors by zinc oxide nanoparticles delays coagulation time and reduces thrombin generation potential in vitro. PLoS ONE 2017, 12, e0181634. [CrossRef]

21. Lu, S.; Duffin, R.; Poland, C.; Daly, P.; Murphy, F.; Drost, E.; Macnee, W.; Stone, V.; Donaldson, K. Efficacy of simple short-term in vitro assays for predicting the potential of metal oxide nanoparticles to cause pulmonary inflammation. Environ. Health Perspect. 2009, 117, 241-247. [CrossRef]

22. Cho, W.S.; Duffin, R.; Poland, C.A.; Howie, S.E.; MacNee, W.; Bradley, M.; Megson, I.L.; Donaldson, K. Metal oxide nanoparticles induce unique inflammatory footprints in the lung: Important implications for nanoparticle testing. Environ. Health Perspect. 2010, 118, 1699-1706. [CrossRef] [PubMed]

23. Pryhuber, G.S.; Huyck, H.L.; Baggs, R.; Oberdörster, G.; Finkelstein, J.N. Induction of chemokines by low-dose intratracheal silica is reduced in TNFR I (p55) null mice. Toxicol. Sci. 2003, 72, 150-157. [CrossRef] [PubMed]

24. Oberdorster, G.; Oberdorster, E.; Oberdorster, J. Nanotoxicology: An emerging discipline evolving from studies of ultrafine particles. Environ. Health Perspect. 2005, 113, 823-839. [CrossRef] [PubMed]

25. Medina, C.; Santos-Martinez, M.; Radomski, A.; Corrigan, O.; Radomski, M. Nanoparticles: Pharmacological and toxicological significance. Br. J. Pharmacol. 2007, 150, 552-558. [CrossRef] [PubMed]

26. Baggs, R.; Ferin, J.; Oberdörster, G. Regression of pulmonary lesions produced by inhaled titanium dioxide in rats. Vet. Pathol. 1997, 34, 592-597. [CrossRef] [PubMed]

27. Geiser, M.; Rothen-Rutishauser, B.; Kapp, N.; Schurch, S.; Kreyling, W.; Schulz, H.; Semmler, M.; Im Hof, V.; Heyder, J.; Gehr, P. Ultrafine particles cross cellular membranes by nonphagocytic mechanisms in lungs and in cultured cells. Environ. Health Perspect. 2005, 113, 1555-1560. [CrossRef]

28. Cho, W.; Choi, M.; Han, B.S.; Cho, M.; Oh, J.; Park, K.; Kim, S.J.; Kim, S.H.; Jeong, J. Inflammatory mediators induced by intratracheal instillation of ultrafine amorphous silica particles. Toxicol. Lett. 2007, 175, 24-33. [CrossRef] [PubMed]

29. Cho, N.; Cheong, T.; Min, J.H.; Wu, J.H.; Lee, S.J.; Kim, D.; Yang, J.; Kim, S.; Kim, Y.K.; Seong, S. A multifunctional core-shell nanoparticle for dendritic cell-based cancer immunotherapy. Nat. Nanotechnol. 2011, 6, 675-682. [CrossRef] [PubMed]

30. Roy, R.; Kumar, D.; Sharma, A.; Gupta, P.; Chaudhari, B.P.; Tripathi, A.; Das, M.; Dwivedi, P.D. ZnO nanoparticles induced adjuvant effect via toll-like receptors and Src signaling in Balb/c mice. Toxicol. Lett. 2014, 230, 421-433. [CrossRef] [PubMed]

31. Håkansson, H.F.; Smailagic, A.; Brunmark, C.; Miller-Larsson, A.; Lal, H. Altered lung function relates to inflammation in an acute LPS mouse model. Pulm. Pharmacol. Ther. 2012, 25, 399-406. [CrossRef]

32. Lee, S.; Lee, D.; Jeon, S.; Kim, S.; Jeong, J.; Kim, J.S.; Cho, J.H.; Park, H.; Cho, W. Combination effect of nanoparticles on the acute pulmonary inflammogenic potential: Additive effect and antagonistic effect. Nanotoxicology 2021, 15, 276-288. [CrossRef] [PubMed]

33. Papanicolaou, D.A.; Wilder, R.L.; Manolagas, S.C.; Chrousos, G.P. The pathophysiologic roles of interleukin-6 in human disease. Ann. Intern. Med. 1998, 128, 127-137. [CrossRef] [PubMed]

34. Croft, M. The role of TNF superfamily members in T-cell function and diseases. Nat. Rev. Immunol. 2009, 9, 271-285. [CrossRef] [PubMed]

35. Tripathi, S.S.; Mishra, V.; Shukla, M.; Verma, M.; Chaudhury, B.P.; Kumar, P.; Chhabra, J.K.; Pandey, H.P.; Paul, B. IL-6 receptormediated lung Th2 cytokine networking in silica-induced pulmonary fibrosis. Arch. Toxicol. 2010, 84, 947-955. [CrossRef] [PubMed]

36. Tripathi, S.; Pandey, H.; Paul, B. Overview of cytokines and receptors in Silicosis. J. App. Pharm. Sci. 2011, 1, 1-5.

37. Qiu, Z.; Fujimura, M.; Kurashima, K.; Nakao, S.; Mukaida, N. Enhanced airway inflammation and decreased subepithelial fibrosis in interleukin 6-deficient mice following chronic exposure to aerosolized antigen. Clin. Exp. Allergy 2004, 34, 1321-1328. [CrossRef] [PubMed]

38. Lee, J.J.; Rosenberg, H.F. (Eds.) Eosinophils in Health and Disease. In Eosinophil Trafficking; Elsevier: Boston, MA, USA, 2013; pp. 121-166.

39. Lee, J.K.; Kim, T.S.; Bae, J.Y.; Jung, A.Y.; Lee, S.M.; Seok, J.H.; Roh, H.S.; Song, C.W.; Choi, M.J.; Jeong, J. Organ-specific distribution of gold nanoparticles by their surface functionalization. J. Appl. Toxicol. 2015, 35, 573-580. [CrossRef] [PubMed]

40. Jeon, S.; Clavadetscher, J.; Lee, D.; Chankeshwara, S.V.; Bradley, M.; Cho, W. Surface charge-dependent cellular uptake of polystyrene nanoparticles. Nanomaterials 2018, 8, 1028. [CrossRef] 